\title{
Facile preparation of hierarchical porous polydopamine microspheres for rapid removal of chromate from the wastewater
}

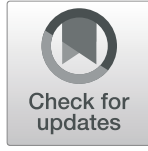

Lin Xiang, Jiayou Lin, Qin Yang, Shaojian Lin, Sheng Chen and Bin Yan * (1)

\begin{abstract}
$\mathrm{Cr}(\mathrm{VI})$ containing industrial wastewaters are highly toxic and carcinogenic, and severely threats living creatures and the environment. Therefore, it is highly desired yet challenging to develop an available and economical adsorbent for simultaneously detoxifying $\mathrm{Cr}(\mathrm{VI})$ anions to $\mathrm{Cr}(\mathrm{III})$ ions and removing them from the wastewater. Here we propose a facile method for rapid removal of $\mathrm{Cr}(\mathrm{VI})$ ions from the wastewater by using a synthetic polydopamine microsphere (PPM) adsorbent with hierarchical porosity. The as-prepared PPM exhibits high Cr(VI) removal capacity of $307.7 \mathrm{mg} / \mathrm{g}$ and an outstanding removal efficiency. They can effectively decrease the $\mathrm{Cr}(\mathrm{VI})$ concentration to lower than $0.05 \mathrm{mg} / \mathrm{L}$ well below the limits for drinking water standard of WHO regulations in $60 \mathrm{~s}$ at $\mathrm{pH}$ 2. More importantly, PPMs can reduce the lethal $\mathrm{Cr}(\mathrm{VI})$ anions to $\mathrm{Cr}(\mathrm{III})$ ions with low toxicity, and simultaneously immobilize them on the matrices of PPMs.
\end{abstract}

Keywords: Porous polydopamine microspheres, $\operatorname{Cr}(\mathrm{VI}), \operatorname{Cr}(\mathrm{III})$, Adsorption and detoxification

\section{Introduction}

$\mathrm{Cr}(\mathrm{VI})$ containing industrial wastewaters have caused severe pollution to water and soil and emerges as an environmental and health crisis in many areas due to their excellent solubility, mobility, bioaccumulation and carcinogenesis $[1,2]$. Many industrial activities, such as leather, electroplating and mining, produce a large amount of $\mathrm{Cr}(\mathrm{VI})$ containing effluents [3]. A worldwide agreement has been reached aiming at reducing or eliminating the thread of $\mathrm{Cr}(\mathrm{VI})$. In China, the sewage discharge standards mandate that the maximum $\mathrm{Cr}(\mathrm{VI})$ concentration of the discharged effluent should be below $0.5 \mathrm{mg} / \mathrm{L}$ [4]; and the World Health Organization (WHO) put forwards even much stricter limits of $0.05 \mathrm{mg} / \mathrm{L}$ for drinking water [5]. Tremendous efforts have been put into the treatment of $\mathrm{Cr}(\mathrm{VI})$ polluted wastewaters, including electrochemical precipitation [6], membrane separation [7],

\footnotetext{
* Correspondence: binyan@scu.edu.cn

College of Biomass Science and Engineering, National Engineering Laboratory for Clean Technology of Leather Manufacture, Sichuan University, Chengdu 610065, China
}

\section{Springer Open}

photocatalysis [8,9], ion exchange [10], and bioremediation [11]. Among these technologies, adsorption is one of the most simple, scalable, effective and economical ones for removing $\mathrm{Cr}(\mathrm{VI})$ [12-17]. Some composites adsorbents, including hydrogel, modified polyaniline, magnetic nanoparticles have been developed for $\mathrm{Cr}(\mathrm{VI})$ removal [3, 18-20]. Nonetheless, these adsorbents still have some inherent drawbacks, such as low adsorption capacity, limited adsorption efficiency at low ion concentration, poor selectivity in complex wastewater, and troublesome regeneration and recovery of adsorbents. More importantly, the adsorbed $\mathrm{Cr}(\mathrm{VI})$ ions on the adsorbents are still very toxic and mobile, which can be easily diffused into the environment to cause the secondary pollution.

By contrast, $\mathrm{Cr}(\mathrm{III})$ is one of the indispensable trace elements in mammals that can regulates insulin and blood sugar levels [21]. In aqueous solution, $\mathrm{Cr}(\mathrm{III})$ forms sparingly soluble $\mathrm{Cr}(\mathrm{OH})_{3}$ or $\mathrm{Cr}_{2} \mathrm{O}_{3}$ precipitate, and can stably exist in the sediment [22]. Many efforts have been devoted to develop advanced materials for 
simultaneously transferring $\mathrm{Cr}(\mathrm{VI})$ anions into $\mathrm{Cr}(\mathrm{III})$ cations and adsorbing the later from the wastewater [8, 16, 23-26]. For example, Wang et al. [23] developed a core-shell magnetic $\mathrm{Fe}_{3} \mathrm{O}_{4} @$ poly(m-phenylenediamine) particles and applied for chromium removal. The developed materials show excellent adsorption capacity of $246.09 \mathrm{mg} / \mathrm{g}$ due to synergistic effect of for chromium reduction and adsorption. Jiang et al. [16] prepared an easily separable humic acid coated magnetite (HA$\mathrm{Fe}_{3} \mathrm{O}_{4}$ ) nanoparticles and employed for effective adsorption and reduction of toxic $\mathrm{Cr}(\mathrm{VI})$ to nontoxic $\mathrm{Cr}(\mathrm{III})$. Despite these great progress, there are still great need to develop other available and economical adsorbents for simultaneously transferring $\mathrm{Cr}(\mathrm{VI})$ anions into $\mathrm{Cr}(\mathrm{III})$ cations and adsorbing the later from the wastewater by using biocompatible materials. Polydopamine (PDA) are a kind of biocompatible polymers that have a wide variety of applications [27-29]. Polydopamine-based adsorbents have abundant functional groups, including phenol groups, catechol, carboxy, o-quinone, amino, imine, which have a strong ability to combine with heavy metals and organic pollutants via chelation, $\pi-\pi$ stacking interactions, electrostatic interaction, hydrogen bonding [30]. Moreover, PDA possesses strong reduction ability and has proved effective in reducing some metal ions such as $\mathrm{Pt}^{3+}, \mathrm{Au}^{3+}$ and $\mathrm{Ag}^{+}$and graphene oxides [31, 32]. Recently, PDA-based functional materials are a kind of adsorbents that have attracted much attention for Cr(VI) removal [25, 26, 33-35]. However, the developed PDA-based adsorbents still suffer from relatively slow adsorption rate at low $\mathrm{Cr}(\mathrm{VI})$ concentration and show limited detoxifying effect of reduction $\mathrm{Cr}(\mathrm{VI})$. These drawbacks can be ascribed to the compact structure of these PDA-based adsorbents, which cannot offer sufficient active sites for reducing $\mathrm{Cr}(\mathrm{VI})$ and binding $\mathrm{Cr}(\mathrm{III})$ because of their low surface area with limited porosity $[15,36,37]$. Thus, we reasoned that porous PDA nanomaterials with hierarchical porosity and high surface area would endow the developed adsorbent with rapid adsorption kinetics and large removal capacity of $\mathrm{Cr}(\mathrm{VI})$ via adsorption and reduction. Nevertheless, it remains a great challenge to develop porous PDA adsorbent materials with hierarchical porosity and most reported strategy to prepare PDA-derived porous materials are relied on carbonization at high temperature to remove the pore agents, thereby resulting in severe loss of active functional groups [38, 39].

For overcoming the above mentioned material defects, we present a facile method to develop hierarchical porous synthetic polydopamine microspheres (PPMs) by combining the slow polymerization of dopamine (DA) with the fast condensation of tetraethoxysilane (TEOS) followed with selective silica etching. The resultant PPMs possess larger surface area of $70.92 \mathrm{~m}^{2} / \mathrm{g}$ with hierarchical porosity, giving rise to abundant available chelating sites for $\mathrm{Cr}(\mathrm{VI})$. PPMs were found to have higher $\mathrm{Cr}(\mathrm{VI})$ removal capacity of $307.7 \mathrm{mg} / \mathrm{g}$ as well as faster adsorption rate when compared with the reported $\mathrm{Cr}(\mathrm{VI})$ adsorbents (Table S1). The as-prepared PPMs can effectively decrease the total $\mathrm{Cr}$ concentration from $10 \mathrm{mg} / \mathrm{L}$ to below $0.5 \mathrm{mg} / \mathrm{L}$ to meet the sewage discharge standards in China in $90 \mathrm{~s}$ and to lower than the $\mathrm{Cr}(\mathrm{VI})$ concentration of $0.05 \mathrm{mg} / \mathrm{L}$ (WHO regulations) in $60 \mathrm{~s}$ at $\mathrm{pH} 2$, outperforming the performances of existing PDAbased adsorbents. Furthermore, PPMs can effectively reduce the acute $\mathrm{Cr}(\mathrm{VI})$ into the low-toxicity $\mathrm{Cr}(\mathrm{III})$ ions and immobilize them on PPM matrices. Compared with photocatalysis and Fenton reduction, PPM shows strong reduction capacity without the need for additional reagents (such as nZVI and $\mathrm{H}_{2} \mathrm{O}_{2}$ ) $[17,40]$ and specific experimental environment (such as, visible-light) [9]. This work demonstrates that PPMs hold great promise for effective and efficient decontamination of $\mathrm{Cr}(\mathrm{VI})$-contained wastewaters.

\section{Material and methods \\ 2.1 Material}

The Chemicals, including DA and tetraethylorthosilicate (TEOS, 99\%), were from Aldrich. Ammonium (25 wt\%), ethanol, hydrochloric $(\mathrm{HCl})$ and $\mathrm{NaOH}$ were from Chemical Co. Ltd. (Chengdu, China). $\mathrm{NaCl}, \mathrm{NaNO}_{3}$, $\mathrm{Na}_{2} \mathrm{SO}_{4}, \mathrm{~K}_{2} \mathrm{Cr}_{2} \mathrm{O}_{7}$ were from Kelong (Chengdu, China). Hydrothermal reactor was obtained from ShengJinKang Instrument Co. Ltd., Chengdu, China.

\subsection{Synthesis of PPMs}

The synthesis scheme for PPMs is shown in Scheme 1. PPMs were synthesized by a facile self-polymerization method under alkaline condition [38]. Typically, a round-bottomed flask was charged with aqueous ammonia $(0.5 \mathrm{~mL}, 25 \%)$, ultrapure water $(40 \mathrm{~mL})$ and absolute ethanol $(12 \mathrm{~mL})$. The resultant mixture was stirred 288 $\mathrm{K}$ for $1 \mathrm{~h}$. Then, TEOS $(0.5 \mathrm{~mL})$ was added to the above mixture and kept stirring for $30 \mathrm{~min}$ to form the silica components. After that, $0.2 \mathrm{~g}$ of DA was added to the above solution and the mixture was stirred for another $24 \mathrm{~h}$ at $288 \mathrm{~K}$. At last, the resultant solution was transferred into a hydrothermal reactor at $453 \mathrm{~K}$ for $24 \mathrm{~h}$. Finally, the obtained product was purified by centrifugation followed with washing with a large amount of ethanol and water until the supernatant is colorless.

\subsection{PPMs material characterization}

The morphology of PPMs was characterized using Tecnai transmission electron microscope (TEM, G2 F20 STWIN, USA) and its surface properties were measured on fully automatic and fast specific surface area and 


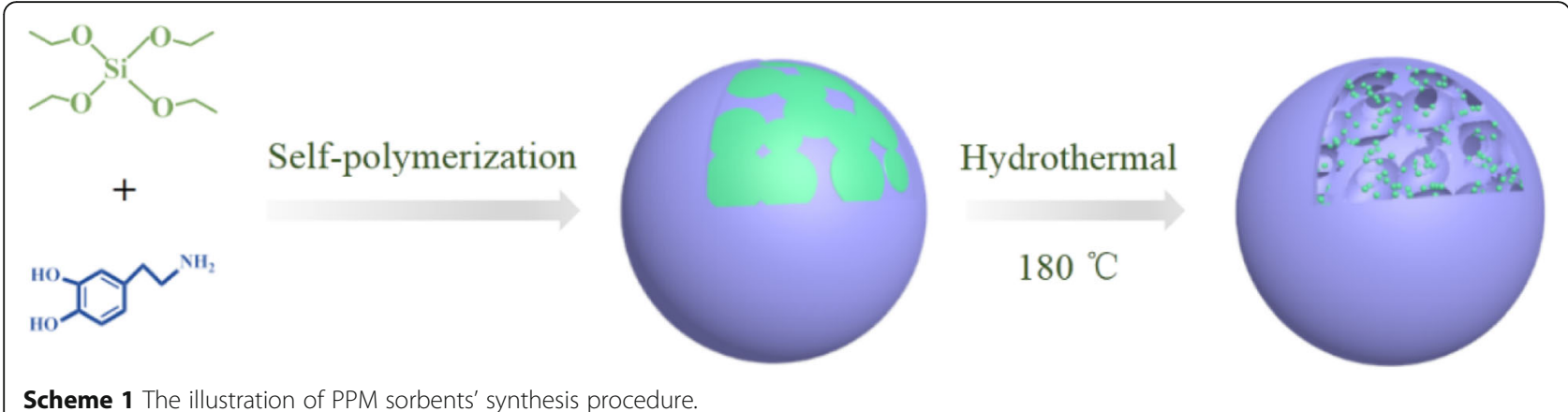

porosity analyzer (Gemini VII 2390, USA). The surface charged properties of PPMs were measured on Malvern zeta potentiometer (Zetasizer Nano ZS, England) while the possible adsorption mechanisms of PPMs to $\mathrm{Cr}(\mathrm{VI})$ were explored via $\mathrm{X}$-ray photoelectron spectroscopy (XPS, AXIS Ultra DLD, Japan). The morphology of the PDA was recorded using a scanning electron microscope with the accelerating voltage of $20 \mathrm{kV}$. FTIR spectra were obtained on Fourier infrared spectra by conventional $\mathrm{KBr}$ disk tablet.

\section{4 $\mathrm{Cr}(\mathrm{VI})$ removal experiments}

This paper explores the factors that could influence the adsorption performance, such as solution $\mathrm{pH}$, competing ions and solution temperature. Moreover, we also investigated the adsorption thermodynamics, adsorption kinetics and reusability of PPMs. The adsorption time was set as $24 \mathrm{~h}$, except for the rapid $\mathrm{Cr}(\mathrm{VI})$ adsorption kinetics experiment. Ultraviolet-visible spectrophotometer (TU-1900 UV-vis spectrometer, China) was used to measure the concentration of $\mathrm{Cr}(\mathrm{VI})$.

The removal capacity, $q_{e}(\mathrm{mg} / \mathrm{g})$, and rate, $\mathrm{M}(\%)$, of PPMs to $\mathrm{Cr}(\mathrm{VI})$ were determined using Eqs. (1) and (2) [41]:

$$
\begin{aligned}
& q_{e}=\left(C_{0}-C_{e}\right) / m * V \\
& M=\left(C_{0}-C_{e}\right) / C_{0} * 100 \%
\end{aligned}
$$

Where $C_{O}(\mathrm{mg} / \mathrm{L})$ stands for the initial concentration of $\mathrm{Cr}(\mathrm{VI})$ solutions and $C_{e}(\mathrm{mg} / \mathrm{L})$ stands for the equilibrium concentration of $\mathrm{Cr}(\mathrm{VI})$ solutions while $m(\mathrm{~g})$ is the mass of PPMs and $V(\mathrm{~L})$ is the volume of $\mathrm{Cr}(\mathrm{VI})$ solutions.

Effect of pH: PPMs $(1 \mathrm{mg})$ were added to $\mathrm{K}_{2} \mathrm{Cr}_{2} \mathrm{O}_{7}$ solutions $(10 \mathrm{~mL}, 100 \mathrm{mg} / \mathrm{L})$ in each glass bottle, and the resulting suspensions were stirred at room temperature for $24 \mathrm{~h}$. The $\mathrm{NaOH}$ or $\mathrm{HCl}$ solutions $(0.1 \mathrm{~mol} / \mathrm{L})$ were used to tune the $\mathrm{pH}$ of these solutions to the desired value.

PPMs adsorption thermodynamics: isothermal adsorption experiments were performed at three temperatures of 298, 313 and $333 \mathrm{~K}$. At desired temperatures, PPMs
(1 mg) were added to different concentrations solution $(5 \sim 100 \mathrm{mg} / \mathrm{L}, 10 \mathrm{~mL})$ and stirred for $24 \mathrm{~h}$. Then, the filtrate was collected by filtering the resulting suspensions via a $0.22-\mu \mathrm{m}$ membrane for measuring the remaining concentrations of $\mathrm{Cr}(\mathrm{VI})$.

Two classic models were used to analyze isothermal adsorption behaviors of PPMs to $\mathrm{Cr}(\mathrm{VI})[36,42]$ :

$$
\begin{aligned}
\text { Langmuir model }: & C_{e} / q_{e} \\
& =1 / K_{L} q_{\max }+C_{e} / q_{\max }
\end{aligned}
$$

Freundlich model : $\lg q_{e}=\lg K_{F}+\lg C_{e} / n$

Where $q_{\max }(\mathrm{mg} / \mathrm{g})$ and $K_{L}$ are the maximum adsorption capacity and a binding constant, respectively; while $K_{F}$ and $n$ represent the Freundlich coefficient and a constant.

Thermodynamic parameters $\left(\Delta H^{0}, \Delta S^{0}\right.$, and $\left.\Delta G^{0}\right)$ can be calculated by Eqs. (5), (6) and (7) [36, 42, 43]:

$$
\begin{aligned}
& K_{c}=q_{e} / C_{e} \\
& \Delta G^{0}=-R T \ln K_{c} \\
& \ln K_{c}=\Delta S^{0} / R-\Delta H^{0} / R T
\end{aligned}
$$

Where $R(8.314 \mathrm{~J} /(\mathrm{mol} \mathrm{K}))$ is gas constant and $K_{c}$ is the adsorption equilibrium constant; while $T(\mathrm{~K})$ is the temperature of the aqueous solution.

Rapid $\mathrm{Cr}(\mathrm{VI})$ adsorption kinetics experiment: PPMs $(18 \mathrm{mg})$ were added to $\mathrm{K}_{2} \mathrm{Cr}_{2} \mathrm{O}_{7}$ solution $(60 \mathrm{~mL}, 10 \mathrm{mg} /$ $\mathrm{L})$. After stirring for the fixed period, the resulting suspension was filtered to collect the filtrate for determining its total $\mathrm{Cr}$ content using ICP-OES (5100 SVDV, USA).

To better understand the adsorption mechanism, two commonly-adopted kinetic models were used to analyze the kinetic results $[37,42]$ :

The pseudo-first-order model:

$$
\ln \left(q_{e}-q_{t}\right)=\ln q_{\text {ecal }}-k_{1} * t / 2.303
$$

The pseudo-second-order model:

$$
t / q_{t}=1 /\left(k_{2} * q_{\text {ecal }}{ }^{2}\right)+\mathrm{t} / q_{\text {ecal }}
$$




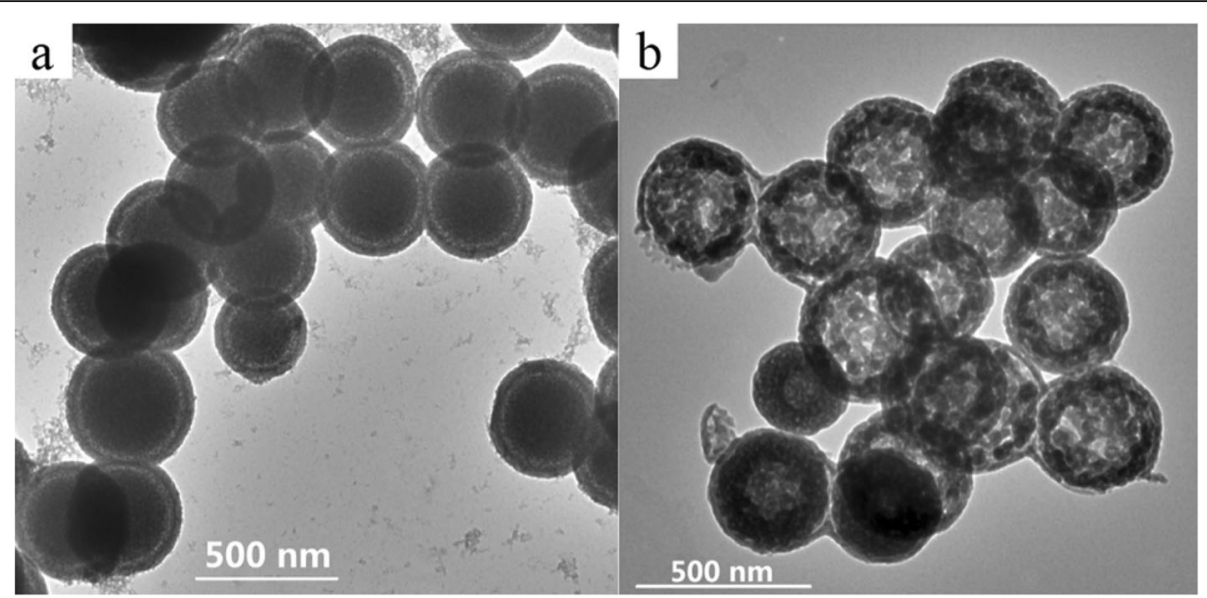

Fig. 1 The TEM characterizations of (a) the PDA/silica nanocomposites and (b) PPMs

$q_{t}$ stands for PPMs' adsorption capacity $(\mathrm{mg} / \mathrm{g})$ in different sample time. $k_{1}$ and $k_{2}$ are the kinetic rates constant. $q_{\text {ecal }}$ stands for the equilibrium adsorption capacity calculated by model fitting.

Effect of completing ions on $\mathrm{Cr}(\mathrm{VI})$ adsorption: weighing three different kinds of salt substances $(\mathrm{NaCl}$, $\left.\mathrm{NaNO}_{3}, \mathrm{Na}_{2} \mathrm{SO}_{4}\right)$ and adding to chromium solution (10 $\mathrm{mL}, 20 \mathrm{mg} / \mathrm{L}, \mathrm{pH}=2$ ) to obtain different molar ratios chromium solution (the molar ratio of anion to $\mathrm{Cr}(\mathrm{VI})$ ). The molar ratios $(\mathrm{R})$ were set to $0,16,32,64$ and 128 , respectively. Then, $0.2 \mathrm{mg}$ PPMs were added to the solution.

Reusability test of PPMs: The reusability of PPMs was investigated to evaluate the cost-effectiveness. Two desorbents were used for the desorption of the chromateloaded adsorbent $(\mathrm{Cr}(\mathrm{VI})$-adsorbed PPMs): one was an acidic solution ( $\mathrm{pH}: 2$, ionic concentration:0.5 mol/L $\mathrm{NaCl}$ ) [15], and the other was a basic solution with 0.5 $\mathrm{mol} / \mathrm{L} \mathrm{NaOH}$ and $\mathrm{NaCl}$ [44]. In brief, the $\mathrm{Cr}(\mathrm{VI})-$ adsorbed PPMs were regenerated by stirring in the desorption solution $(10 \mathrm{~mL})$ for $24 \mathrm{~h}$ and then collected by centrifuging and washing with water until the supernatant is colorless. The regenerated PPMs were reused for $\mathrm{Cr}(\mathrm{VI})$ removal.

\section{Results and discussion}

3.1 Synthesis and characterizations of the PPMs

The PPMs were synthesized with a combination of a one-step Stöber route and a sequent selective silica etching as shown in Scheme 1. In brief, the PDA/silica nanocomposites were first developed with TEOS as the structure assistant and DA as the polydopamine precursor in an alkaline mixture containing ammonia, ethanol and water. As shown in Fig. 1a, the PDA/silica nanocomposites have a distinct core-shell structure with average diameter of $410 \mathrm{~nm}$ (Fig. S1). Then silica components in the resultant PDA/silica nanocomposites were selectively etched following a reported procedure via a hydrothermal treatment at weakly alkaline condition, resulting in the desired PPMs [38]. It is obvious that the resulting PPMs maintain the integrity of the PDA/silica nanocomposites with similar diameter and the silica component among PPMs has been partially etched, generating a hierarchical nanostructure (Fig. 1b
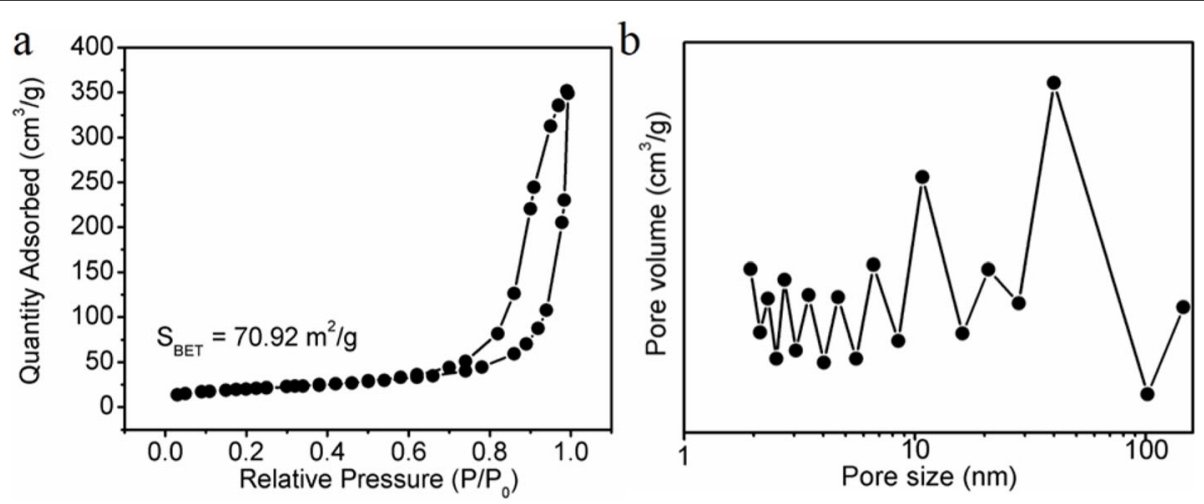

Fig. 2 a $\mathrm{N}_{2}$ sorption isotherms of PPMs collected at $77 \mathrm{~K} ; \mathbf{b}$ pore size distributions of PPMs 

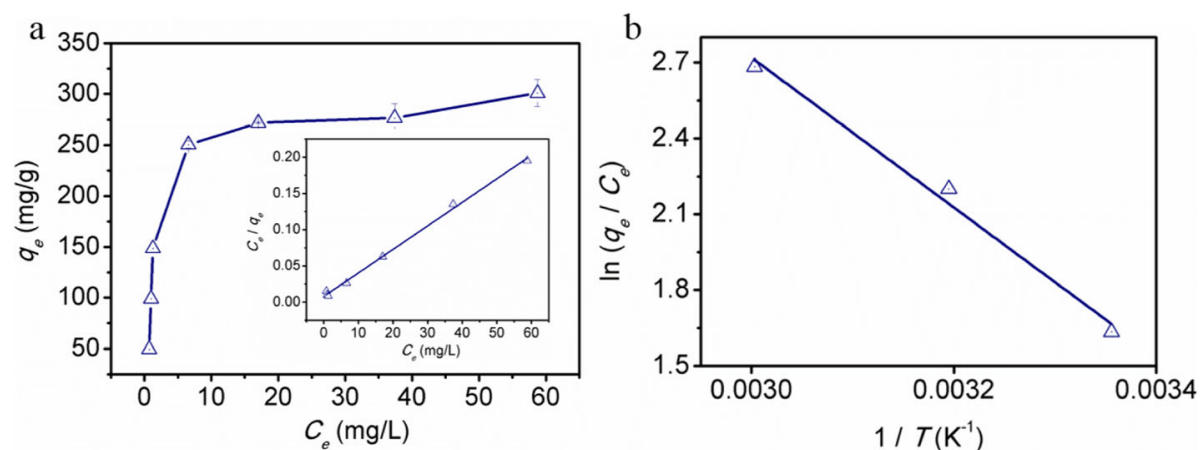

Fig. 3 a PPMs' adsorption isotherms to $\mathrm{Cr}(\mathrm{VI})$ at $298 \mathrm{~K}$ (Inset: Linear Langmuir model); b the plots of InK $\mathrm{K}_{a}$ versus of 1/T

and Fig. S2a). This special hierarchical nanostructure confers the developed PPMs with high surface area and hierarchical porosity, which was verified by BrunauerEmmett-Teller (BET) measurement. PPMs provided a type IV isotherms indicating mesoporosity. According to the nitrogen adsorption isotherm, BET surface area of PPMs is calculated for $70.92 \mathrm{~m}^{2} / \mathrm{g}$ (Fig. 2a), higher than that of PDA-based adsorbent materials which are previously reported [45]. Meanwhile, the pore size distribution of PPMs indicates that PPMs have hierarchical porosity ranging from 1 to $50 \mathrm{~nm}$ (Fig. 2b). The combination of high surface area and hierarchical porosity ensure abundant chelation sites for $\mathrm{Cr}(\mathrm{VI})$ adsorption [46]. From FTIR spectra (Fig. S2b), PPM preserves all the functional groups of polydopamine, including 1246 $\mathrm{cm}^{-1}(\mathrm{C}-\mathrm{N}$ stretching mode $), 1622 \mathrm{~cm}^{-1}(\mathrm{~N}-\mathrm{H}$ bending overlapped with $\mathrm{C}=\mathrm{C}$ resonance vibrations), $3420 \mathrm{~cm}^{-1}$ ( the surface adsorbed water and hydroxyl groups) [47, 48 ] and $1065 \mathrm{~cm}^{-1}$ (the $\mathrm{Si}-\mathrm{O}-\mathrm{Si}$ groups stretching vibration of silica nano-particles) [47].

\subsection{High $\mathrm{Cr}(\mathrm{VI})$ removal capacity of PPMs}

High chromate removal capacity is very important for the as-prepared adsorbent to hold promise in its practical application. Therefore, the $\mathrm{Cr}(\mathrm{VI})$ equilibrium removal capacity of PPMs were obtained by adding the PPMs in a series of $\mathrm{Cr}(\mathrm{VI})$ concentrations solutions $(\mathrm{V}=10 \mathrm{~mL}, 5 \sim 100 \mathrm{mg} / \mathrm{L})$ at $298 \mathrm{~K}$, and the isotherm results are shown in Fig. 3a. At optimal $\mathrm{pH}=2$ (Fig. S4a), the adsorption behavior of PPMs can be better described by Langmuir model with a higher coefficient of 0.997

Table 1 Fitting parameters of thermodynamic adsorption under different temperatures

\begin{tabular}{|c|c|c|c|c|c|c|c|}
\hline \multirow[t]{2}{*}{ Materials } & \multirow{2}{*}{$\begin{array}{l}\mathrm{T} \\
(\mathrm{K})\end{array}$} & \multicolumn{3}{|l|}{ Langmuir } & \multicolumn{3}{|c|}{ Freundlich } \\
\hline & & $q_{\max }(\mathrm{mg} / \mathrm{g})$ & $\mathrm{K}_{\mathrm{L}}(\mathrm{L} / \mathrm{mg})$ & $R^{2}$ & $\overline{K_{F}(L / g)}$ & $n$ & $R^{2}$ \\
\hline \multirow[t]{3}{*}{ PPMs } & 298 & 307.7 & 0.419 & 0.997 & 94.990 & 3.030 & 0.727 \\
\hline & 313 & 602.4 & 0.083 & 0.988 & 221.958 & 5.583 & 0.973 \\
\hline & 333 & 636.9 & 0.207 & 0.995 & 314.409 & 7.293 & 0.769 \\
\hline
\end{tabular}

compared with Freundlich one (inset of Fig. 3a and Fig. S5a). The PPMs were determined to have maximum adsorption capacity of $307.7 \mathrm{mg} / \mathrm{g}$, outperforming most previously reported PDA derived materials (Table S1). Meanwhile, the effect of adsorbent dose on adsorption performance of PPM was also investigated (Fig. S3). The result shows that increasing the adsorbent dose induces a decrease in the adsorption capacity of PPMs.

Meanwhile, isothermal adsorption experiment was also performed to study the thermodynamic behavior of PPMs. The results show that PPMs' adsorption capacity to $\mathrm{Cr}(\mathrm{VI})$ is highly temperature-dependent (Table 1 and Fig. S5b). Increasing the reaction solution temperature from 288 to $333 \mathrm{~K}$ results in more than $50 \%$ enhancement of the adsorption capacity of PPMs, reaching to $636.94 \mathrm{mg} / \mathrm{g}$. In all the three cases, PPMs' adsorption capacity to $\mathrm{Cr}(\mathrm{VI})$ can be better fitted by the Langmuir model, suggesting a homogeneous monolayer adsorption of $\mathrm{Cr}(\mathrm{VI})$ on PPMs (Fig. S5c, d).

To better explore the effect of temperature on PPMs' adsorption to $\mathrm{Cr}(\mathrm{VI})$, we derived key thermodynamic parameters, such as $\Delta S^{0}, \Delta H^{0}$ and $\Delta G^{0}$, from the adsorption isotherms under different temperatures (Fig. $3 \mathrm{~b}$ and Table 2). We can observe that the adsorption reactions at all three temperatures yield negative $\Delta G^{0}$ values, reflecting that PPMs adsorb $\mathrm{Cr}(\mathrm{VI})$ from the wastewater spontaneously, and increasing the temperature favors PPMs' adsorption to $\mathrm{Cr}(\mathrm{VI})$ ensured by a greater $\Delta \mathrm{G}^{0}$ values. This result is also confirmed by the change of $\Delta H^{0}$ value. The positive $\Delta H^{0}$ (i.e., $18.15124 .621 \mathrm{~kJ} / \mathrm{mol}$ ) indicates that the adsorption process by PPMs is an endothermic reaction, Thus, increasing the temperature of the reaction system is more conducive to the adsorption.

\subsection{Rapid $\mathrm{Cr}(\mathrm{VI})$ adsorption kinetics of PPMs}

Since rapid purification of heavy metals is crucial to the practical application of a material, it is necessary to explore the adsorption kinetics of PPMs. Therefore, the removal efficiency of PPMs to $\mathrm{Cr}(\mathrm{VI})$ was determined by 
Table 2 The thermodynamic parameters of $\Delta H^{0}, \Delta S^{0}$ and $\Delta G^{0}$

\begin{tabular}{llcc}
\hline$T(K)$ & $\Delta G^{0}(\mathrm{~kJ} / \mathrm{mol})$ & $\Delta \mathrm{H}^{0}(\mathrm{~kJ} / \mathrm{mol})$ & $\Delta S^{0}(\mathrm{~kJ} / \mathrm{mol} \mathrm{K})$ \\
\hline 298 & -4.405 & 24.621 & 0.096 \\
313 & -5.268 & & \\
333 & -6.424 & & \\
\hline
\end{tabular}

investigating the $\mathrm{Cr}(\mathrm{VI})$ adsorption kinetics of PPMs. As shown in Fig. 4a, PPMs demonstrate a rapid $\mathrm{Cr}(\mathrm{VI})$ adsorption, which can effectively decrease the total Cr concentration from $10 \mathrm{mg} / \mathrm{L}$ to below $0.5 \mathrm{mg} / \mathrm{L}$ in $90 \mathrm{~s}$ to meet the sewage discharge standards in China. In addition, PPMs are able to generate a purified water with the $\mathrm{Cr}(\mathrm{VI})$ concentration lower than the acceptable limit of $0.05 \mathrm{mg} / \mathrm{L}$ for potable water mandated by WHO. To reliably represent PPMs' adsorption kinetics to $\mathrm{Cr}(\mathrm{VI})$, we also fitted the kinetic results with two kinetic models. The fitting results demonstrated that PPMs' adsorption kinetics can be better described by the pseudo-secondorder kinetic model with a higher $R^{2}(>0.999)$ when compared to that of the pseudo-first-order one (Fig. $4 \mathrm{~b}$ and Table 3), suggesting that PPMs' adsorption process is controlled by chemisorption. The adsorption rate constant $k_{2}$ was determined to be up to $3.39 \mathrm{~g} /(\mathrm{mg} \mathrm{min})$, which is higher than solid PDA microspheres [36] and the highest among all reported PDA derived materials for chromate removal [37, 44]. We attribute this rapid adsorption kinetics of PPMs to the hierarchical porosity and high BET surface area.

\subsection{Highly selectivity of PPMs to $\mathrm{Cr}(\mathrm{VI})$ from complex wastewater}

In practical applications, it is critical for an adsorbent to possess high selectivity for removing $\mathrm{Cr}(\mathrm{VI})$ because the discharged wastewater commonly contains a large number of competing ions [49]. Therefore, the selectivity test was carried out by using $\mathrm{K}_{2} \mathrm{Cr}_{2} \mathrm{O}_{7}$ solutions containing $\mathrm{Cl}^{-}, \mathrm{NO}_{3}{ }^{-}$and $\mathrm{SO}_{4}{ }^{2-}$ ions. These ions are commonly existed in the discharged effluents. As shown in Fig. 5, PPMs demonstrate an excellent adsorption selectivity for $\mathrm{Cr}(\mathrm{VI})$ even with these competing ions at high concentrations. Interestingly, instead of undermining the PPMs' removal capacity to $\mathrm{Cr}(\mathrm{VI})$, when the $\mathrm{SO}_{4}{ }^{2-}$ concentration changes from 0 to $590 \mathrm{mg} / \mathrm{L}$, the removal capacity slightly increases by $10 \%$ and reaches $167 \mathrm{mg} / \mathrm{g} . \mathrm{Cl}^{-}$and $\mathrm{NO}_{3}{ }^{-}$ion exhibit an obvious enhancement on PPMs' removal capacity to $\mathrm{Cr}(\mathrm{VI})$. For example, increasing the $\mathrm{Cl}^{-}$concentration from 0 to $1747 \mathrm{mg} / \mathrm{L}$ will achieve a peak in the removal capacity first and then decrease. However, compared to that without competitive ions, PPMs' removal capacity of $\mathrm{Cr}(\mathrm{VI})$ at all the conditions are increased. Competing ions can influence the $\mathrm{Cr}(\mathrm{VI})$ adsorption of PPM in two ways. At a low ionic strength, anions, especially the smaller anions such as $\mathrm{Cl}^{-}$, can enter PPMs structure, causing the polymer chains to expand/swell PPMs' matrices for more adsorption sites and increasing the adsorption capacity of PPM to $\mathrm{Cr}(\mathrm{VI})$ [50]. However, further increasing the concentration of these anions will result in strong electrostatic competition with $\mathrm{Cr}(\mathrm{VI})$ adsorption, thus decreasing its removal capacity.

\subsection{Easy regeneration and recovery of adsorbents for recycling}

Although alkaline desorption method has been commonly adopted for regenerating the $\mathrm{Cr}(\mathrm{VI})$-adsorbed adsorbents, it was found that under strong alkaline conditions, PPMs will be aggregated, which result in low dispersibility and poor adsorption performance in the next adsorption cycle [51]. On the contrary, the regenerated PPMs via acidic condition demonstrate an outstanding dispersibility and maintain a good adsorption performance in the following cycles. Moreover, the PPMs can be easily regenerated and show a wonderful recyclability. We used $\mathrm{HCl}$ solution $(0.01 \mathrm{~mol} / \mathrm{L})$ to wash and regenerate the $\mathrm{Cr}(\mathrm{VI})$-adsorbed PPMs. This
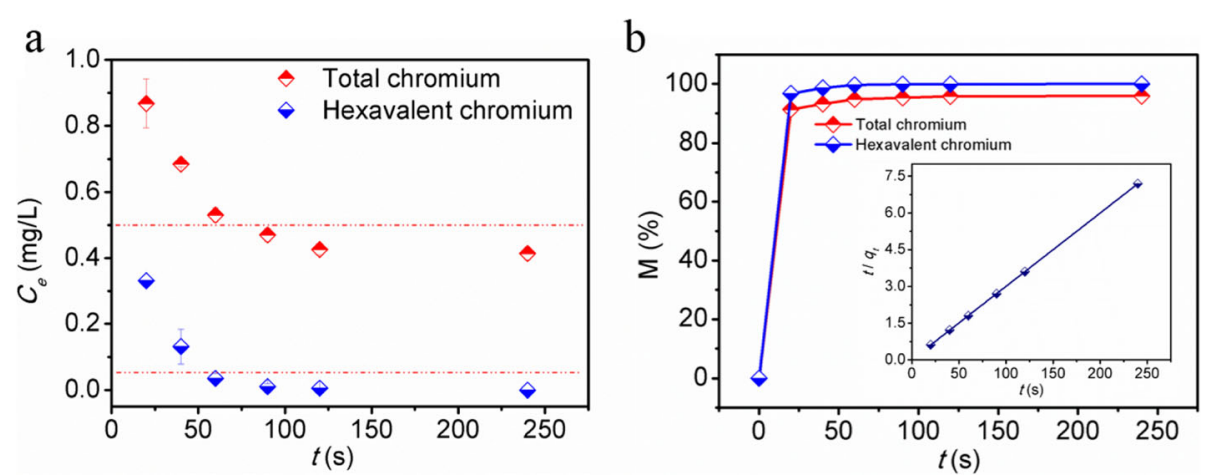

Fig. 4 a $\mathrm{Cr}(\mathrm{VI})$ and total chromium sorption kinetics of PPMs; $\mathbf{b}$ the adsorption curve of $\mathrm{Cr}(\mathrm{VI})$ and total chromium removal rate versus reaction time, inset shows the fitting data of the pseudo-second-order kinetic model of $\mathrm{Cr}(\mathrm{VI})$ adsorption. (Condition: $\mathrm{PPMs}_{18} \mathrm{mg}_{1} \mathrm{~K}_{2} \mathrm{Cr}_{2} \mathrm{O}_{7}$ solution with $\mathrm{Cr}(\mathrm{Vl})$ concentration of $10 \mathrm{mg} / \mathrm{L}, 60 \mathrm{~mL}, \mathrm{pH}=2)$ 
Table 3 Kinetic adsorption model fitting data

\begin{tabular}{|c|c|c|c|c|c|c|}
\hline \multirow{2}{*}{$\begin{array}{l}\text { Mass } \\
\text { ration } \\
\text { of } \\
\text { Cr(VI) } \\
\text { and } \\
\text { PPMs } \\
\end{array}$} & \multicolumn{3}{|c|}{ Pseudo-first-order model } & \multicolumn{3}{|c|}{ Pseudo-second-order model } \\
\hline & $\mathrm{q}_{\text {ecal }}(\mathrm{mg} / \mathrm{g})$ & $\mathrm{k}_{1}(/ \mathrm{min})$ & $R^{2}$ & $\overline{q_{\text {ecal }}(\mathrm{mg} / \mathrm{g})}$ & $\mathrm{k}_{2}(\mathrm{~g} / \mathrm{mg} \min )$ & $R^{2}$ \\
\hline $1: 30$ & 2.071 & 2.508 & 0.957 & 33.422 & 3.39 & 0.999 \\
\hline
\end{tabular}

procedure can effectively regenerate the PPMs and guarantee an remarkable recyclability with inappreciable loss of $\mathrm{Cr}(\mathrm{VI})$ adsorption capacity of PPMs. It was found that after 4 regeneration and reuse cycles, the PPMs can still retain $97 \%$ of the original adsorption capacity (Fig. S6).

\section{6 $\mathrm{Cr}(\mathrm{VI})$ adsorption mechanisms of PPMs via reduction and immobilization}

To disclose possible $\mathrm{Cr}(\mathrm{VI})$ removal mechanism of PPMs, we carried out XPS characterization on PPMs and the $\mathrm{Cr}(\mathrm{VI})$-adsorbed PPMs. As shown in Fig. 6a, both PPMs samples display peaks of $\mathrm{O} 1 \mathrm{~s}, \mathrm{C} 1 \mathrm{~s}$ and $\mathrm{N} 1 \mathrm{~s}$, confirming that PPMs are mainly composed of PDA polymers. By contrast, Fig. 6b shows the $\mathrm{Cr}(\mathrm{VI})$-adsorbed PPMs have distinct $\mathrm{Cr} 2 \mathrm{p}$ peak, which can be subdivided into different peaks belonging to $\mathrm{Cr}(\mathrm{VI})$ and $\mathrm{Cr}(\mathrm{III})$ species [3, 37]. It can find that the majority of $\mathrm{Cr}$ components are in $\mathrm{Cr}$ (III) state, as the content of $\mathrm{Cr}$ (III) peaks at $576.61 \mathrm{eV}, \quad 577.54 \mathrm{eV}$ and $586.62 \mathrm{eV}$ account for about $80 \%$ of the total chromium. Therefore, PPMs has a strong reduction effect on $\mathrm{Cr}(\mathrm{VI})$ during the adsorption. This reduction effect was also confirmed by the change of $\mathrm{O} 1 \mathrm{~s}$ by two materials (PPMs and $\mathrm{Cr}(\mathrm{VI})$-adsorbed PPMs). Compared to that before adsorption, the peaks belonging to the phenolic hydroxyl group $(-\mathrm{C}-\mathrm{OH})$ dramatically decrease while these belonging to the quinone group (R-CO-R) increase significantly after adsorption (Fig. 6c) [52]. These results indicate that phenolic hydroxyl groups on PPMs can help reduce $\mathrm{Cr}(\mathrm{VI})$ anion and transfer to its counterpart $\mathrm{Cr}$ (III) ions [30]. Meanwhile, the binding energy of the $\mathrm{N} 1 \mathrm{~s}$ at $400.14 \mathrm{eV}$ shifts to that of $399.88 \mathrm{eV}$ after adsorption. The typical $\mathrm{N} 1 \mathrm{~s}$ peaks can be assumed into three peaks at $399.05 \mathrm{eV}$ (=N-R), $400.14 \mathrm{eV}$ (R-NH-R), $400.92 \mathrm{eV}\left(\mathrm{R}-\mathrm{NH}_{2}\right)$ before adsorption, which clearly shift to $398.68 \mathrm{eV}$ (= $\mathrm{N}-\mathrm{R}), 399.95 \mathrm{eV}$ (R-NH-R), $400.71 \mathrm{eV}\left(\mathrm{R}-\mathrm{NH}_{2}\right)$ after adsorption (Fig. 6d). The peak shifting indicate that the regional bonding environment near nitrogen species of PPM has changed after $\mathrm{Cr}(\mathrm{VI})$ adsorption and reveal the possible strong interaction between nitrogen and chromium species [53, 54].

Therefore, the mechanism for the $\mathrm{Cr}(\mathrm{VI})$ adsorption of PPMs can be summarized in three steps. Firstly, PPMs enrich chromate on their matrices via electrostatic attraction (see Fig. S3b and S3c). Then, the reductive groups of PPMs such as the phenolic hydroxyl are able to reduce the acute $\mathrm{Cr}$ (VI) anions to form the benign $\mathrm{Cr}(\mathrm{III})$ ions. Finally, the nitrogen and oxygen species,

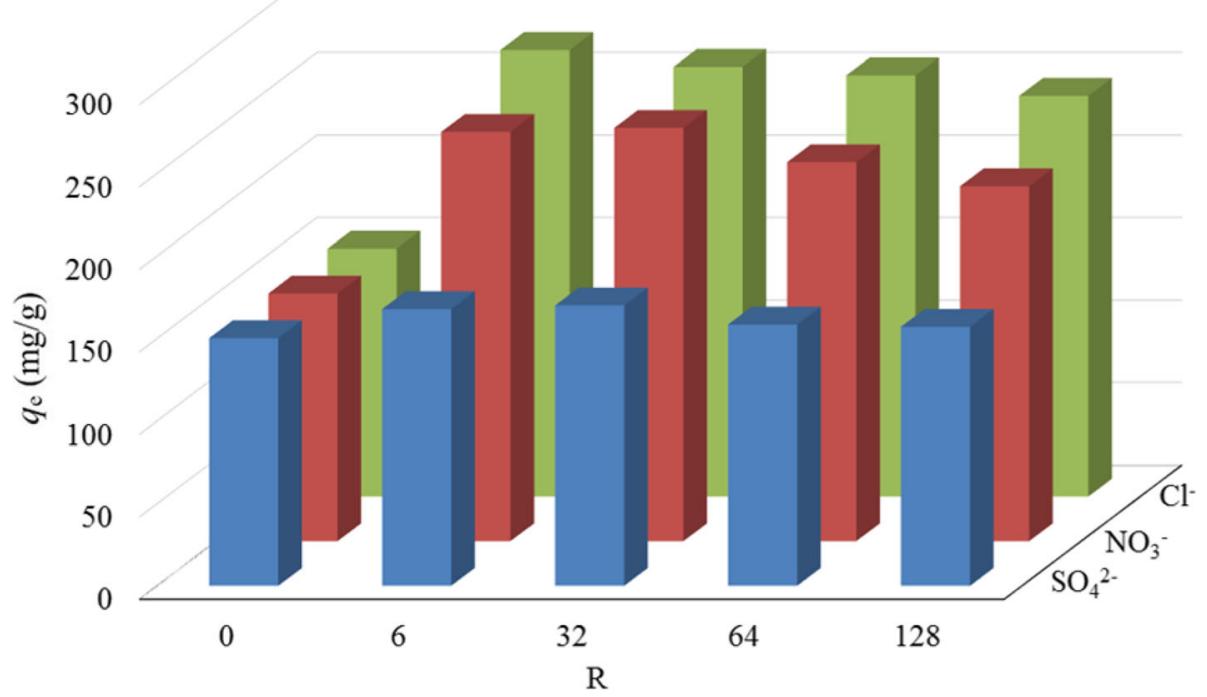

Fig. 5 The effect of competitive ions on $\mathrm{Cr}(\mathrm{Vl})$ remove of PPMs. (Condition: PPMs $0.2 \mathrm{mg}$, initial $\mathrm{Cr}(\mathrm{Vl})=20 \mathrm{mg} / \mathrm{L}, 10 \mathrm{~mL}$ ) 

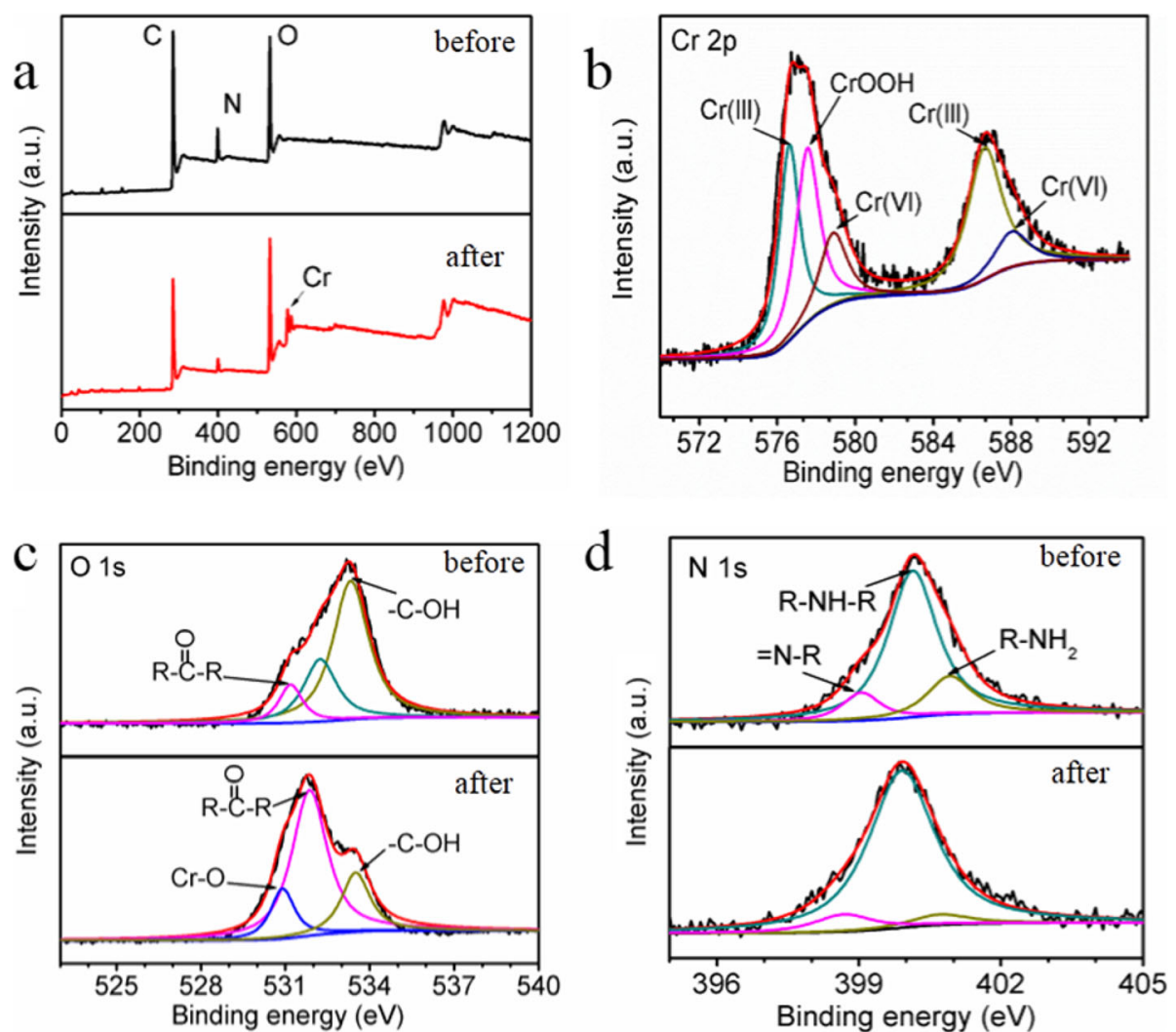

Fig. 6 a XPS spectra investigation of PPMs and Cr(VI)-adsorbed PPMs; $\mathbf{b} \mathrm{Cr} 2 \mathrm{p}$ spectral survey to the Cr(VI)-adsorbed PPMs; c O 2p and d N $1 \mathrm{~s}$ high-resolution spectra of PPMs and the Cr(VI)-adsorbed PPMs

such as amine and phenol, on PPMs provide lone pair electrons to coordinate the $\mathrm{Cr}$ species, achieving the aim at elimination and detoxing $\mathrm{Cr}(\mathrm{VI})$.

\section{Conclusions}

We have demonstrated a facile approach to develop porous polydopamine microspheres (PPMs) with hierarchical porosity for efficiently removing $\mathrm{Cr}(\mathrm{VI})$ from the wastewater via adsorption and reduction. The developed PPMs possess hierarchical porosity ranging from 2 to 50 $\mathrm{nm}$ with high surface area of $70.92 \mathrm{~m}^{2} / \mathrm{g}$, giving rise to abundant available coordinating sites for $\mathrm{Cr}(\mathrm{VI})$ adsorption. These outstanding properties endow PPMs with high removal capacity to $\mathrm{Cr}(\mathrm{VI})$ of $421.9307 .7 \mathrm{mg} / \mathrm{g}$, and rare rapid kinetics for $\mathrm{Cr}(\mathrm{VI})$ removal with $k_{2}$ about $22.5923 .39 \mathrm{~g} /(\mathrm{mg} \mathrm{min})$. Meanwhile, PPMs rapidly decrease the $\mathrm{Cr}(\mathrm{VI})$ concentration from 10 to below 0.5 $\mathrm{mg} / \mathrm{L}$ to meet the sewage discharge standards in China in $20 \mathrm{~s}$ and to lower than $0.05 \mathrm{mg} / \mathrm{L}$ in $60 \mathrm{~s}$ at $\mathrm{pH} 2$. Moreover, PPMs can retain high adsorption capacity in high concentration competitive ion solutions. More important, PPMs can synergistically reduce lethal $\mathrm{Cr}(\mathrm{VI})$ anions to $\mathrm{Cr}$ (III) and immobilize the latter on the matrices. The as-prepared PPMs show great promises in treating the $\mathrm{Cr}(\mathrm{VI})$-containing wastewater and eliminating its thread to the environment and living creatures.

\section{Supplementary information}

Supplementary information accompanies this paper at https://doi.org/10. 1186/s42825-020-00036-X.

Additional file 1: The supporting information include 6 figures and 1 table: Statistical analysis of particle size of PDA/silica nanocomposites; the SEM image and FTIR graph of PPM; the effect of adsorbent dose on PPMs' adsorption performance. (Cr(VI) concentration of $100 \mathrm{mg} / \mathrm{L}, 10 \mathrm{~mL}$ ); the relation of solution $\mathrm{pH}$ and PPMs adsorption of $\mathrm{Cr}(\mathrm{VI})$; Zeta potential charges of PPMs; $\mathrm{Cr}(\mathrm{VI})$ species distribution at different solution $\mathrm{pH}$; linear Freundlich model of adsorption isotherms of $\mathrm{Cr}(\mathrm{VI})$ onto PPMs at $298 \mathrm{~K}$; adsorption isotherms of $\mathrm{Cr}(\mathrm{VI})$ onto PPMs at different temperatures; linear Langmuir model at different temperatures; linear Freundlich model at different temperatures; the recyclability of PPMs for removing Cr(M). (Recycling conditions: PPMs $10 \mathrm{mg}$, initial $\mathrm{Cr}(\mathrm{VI})=$ $50 \mathrm{mg} / \mathrm{L}, 10 \mathrm{~mL}$ ). Figure S1. Statistical analysis of particle size of PDA/silica nanocomposites. Figure S2. The SEM image and FIIR graph of PPM. Figure S3. The effect of adsorbent dose on PPMs' adsorption performance. (CrMI) concentration of $100 \mathrm{mg} / \mathrm{L}, 10 \mathrm{~mL}$ ). Figure S4. (a) The relation of solution $\mathrm{pH}$ and PPMs adsorption of Cr(V)); (b) Zeta potential charges of PPMs; (c) Cr(VI) species distribution at different solution pH. Figure S5. (a) Linear Freundlich model of adsorption isotherms of Cr(MI) onto PPMs at 298 K; (b) adsorption isotherms of $\mathrm{Cr}(\mathrm{M})$ onto PPMs at different temperatures; (c) linear Langmuir model at different temperatures; (d) linear Freundlich model at different temperatures. Figure S6. The recyclability of PPMs for removing $\mathrm{Cr}(\mathrm{M})$ ). (Recycling conditions: PPMs $10 \mathrm{mg}$, initial $\mathrm{Cr}(\mathrm{Ml})=50 \mathrm{mg} / \mathrm{L}, 10 \mathrm{~mL}$ ). Table $\mathbf{S 1}$. Selected $\mathrm{Cr}(\mathrm{M})$ sorption data for reported adsorbents. 


\section{Abbreviations}

PPMs: Porous polydopamine microspheres; DA: Dopamine;

TEOS: Tetraethoxysilane

\section{Acknowledgements}

We would like to thank Prof. Meiju Xie and Prof. Shanling Wang in the Analytical \& Testing Center of Sichuan University for TEM measurements, and thank Dr. Sha Deng for the experimental assistance.

\section{Authors' contributions}

The author(s) read and approved the final manuscript.

\section{Funding}

This work was supported by the National Natural Science Foundation of China (no. 21876119), the Fundamental Research Funds for the Central Universities (no. YJ201732) and Sichuan Science and Technology Program (no. 2018GZ0381)

\section{Availability of data and materials}

The raw/processed data required to reproduce these findings cannot be shared at this time as the data also forms part of an ongoing study.

\section{Competing interests}

The authors declare that they have no known competing financial interests or personal relationships that could have appeared to influence the work reported in this paper.

Received: 21 April 2020 Accepted: 14 August 2020

\section{Published online: 25 August 2020}

\section{References}

1. Abubakr AH, Gurman SJ, Murphy LM, Ashlee P, Smith TJ, Gardiner PHE. Remediation of chromium(VI) by a methane-oxidizing bacterium. Environ Sci Technol. 2010;44:400-5

2. Barros MASD, Silva EA, Arroyo PA, Tavares CRG, Schneider RM, Suszek M, Sousa-Aguiar EF. Removal of $\mathrm{Cr}(\mathrm{III})$ in the fixed bed column and batch reactors using as adsorbent zeolite NaX. Chem Eng Sci. 2004;59:5959-66.

3. Dong K, Liu Q, Wei G, Hu T, Yao J, Zhang X, Gao T. Mussel-inspired magnetic adsorbent: adsorption/reduction treatment for the toxic $\mathrm{Cr}(\mathrm{VI})$ from simulated wastewater. J Appl Polym Sci. 2018;135:46530.

4. Zhang H, Li P, Wang Z, Cui W, Zhang Y, Zhang Y, Zheng S, Zhang Y. Sustainable disposal of $\mathrm{Cr}(\mathrm{VI})$ : adsorption-reduction strategy for treating textile wastewaters with amino-functionalized boehmite hazardous solid wastes. ACS Sustain Chem Eng. 2018;6:6811-9.

5. Li P, Fu T, Gao X, Zhu W, Han C, Liu N, He S, Luo Y, Ma W. Adsorption and reduction transformation behaviors of $\mathrm{Cr}(\mathrm{VI})$ on mesoporous polydopamine/titanium dioxide composite nanospheres. J Chem Eng Data. 2019:64:2686-96.

6. Meunier N, Drogui P, Montané C, Hausler R, Mercier G, Blais JF. Comparison between electrocoagulation and chemical precipitation for metals removal from acidic soil leachate. J Hazard Mater. 2006;137:581-90.

7. Zhong Y, Qiu X, Chen D, Li N, Xu Q, Li H, He J, Lu J. Flexible electrospun carbon nanofiber/tin(IV) sulfide core/sheath membranes for photocatalytically treating chromium(VI)-containing wastewater. ACS Appl Mater Interfaces. 2016:8:28671-7.

8. Liu W, Ni J, Yin X. Synergy of photocatalysis and adsorption for simultaneous removal of $\mathrm{Cr}(\mathrm{VI})$ and $\mathrm{Cr}(\mathrm{III})$ with $\mathrm{TiO}_{2}$ and titanate nanotubes. Water Res. 2014;53:12-25.

9. Deng F, Lu X, Luo Y, Wang J, Che W, Yang R, Luo X, Luo S, Dionysiou DD. Novel visible-light-driven direct Z-scheme $\mathrm{CdS} / \mathrm{CulnS}_{2}$ nanoplates for excellent photocatalytic degradation performance and highly-efficient $\mathrm{Cr}(\mathrm{VI})$ reduction. Chem Eng J. 2018;361:1451-61.

10. Xing $Y$, Chen $X$, Wang D. Electrically regenerated ion exchange for removal and recovery of $\mathrm{Cr}(\mathrm{VI})$ from wastewater. Environ. Sci. Technol. 2007:41:1439-43.

11. Cheng Y, Yan F, Huang F, Chu W, Pan D, Chen Z, Zheng J, Yu M, Lin Z, Wu Z. Bioremediation of $\mathrm{Cr}(\mathrm{VI})$ and immobilization as $\mathrm{Cr}(\mathrm{III})$ by Ochrobactrum anthropi. Environ. Sci. Technol. 2010:44:6357-63.

12. Liang $H$, Song $B$, Peng $P$, Jiao $G$, Yan $X$, She D. Preparation of threedimensional honeycomb carbon materials and their adsorption of $\mathrm{Cr}(\mathrm{Vl})$. Chem Eng J. 2019;367:9-16.
13. Daneshvar E, Zarrinmehr MJ, Kousha M, Hashtjin AM, Saratale GD, Maiti A, Vithanage $M$, Bhatnagar A. Hexavalent chromium removal from water by microalgal-based materials: adsorption, desorption and recovery studies. Bioresour Technol. 2019:293:122064.

14. Yu S, Wang X, Yao W, Wang J, Ji Y, Ai Y, Alsaedi A, Hayat T, Wang X. Macroscopic, spectroscopic, and theoretical investigation for the interaction of phenol and Naphthol on reduced Graphene oxide. Environ Sci Technol. 2017; $51: 3278-86$.

15. Nematollahzadeh A, Seraj S, Mirzayi B. Catecholamine coated maghemite nanoparticles for the environmental remediation: hexavalent chromium ions removal. Chem Eng J. 2015;277:21-9.

16. Wang T, Zhang L, Li C, Yang W, Song T, Tang C, Meng Y, Dai S, Wang H, Chai L, Luo J. Synthesis of Core-Shell magnetic $\mathrm{Fe}_{3} \mathrm{O}_{4} @$ poly(mPhenylenediamine) particles for chromium reduction and adsorption. Environ Sci Technol. 2015:49:5654-62.

17. Vilardi G, Ochando-Pulido JM, Verdone N, Stoller M, Di Palma L. On the removal of hexavalent chromium by olive stones coated by iron-based nanoparticles: equilibrium study and chromium recovery. J Clean Prod. 2018;190:200-10.

18. Das S, Chakraborty P, Ghosh R, Paul S, Nandi AK. Folic acid-polyaniline hybrid hydrogel for adsorption/reduction of chromium (VI) and selective adsorption of anionic dye from water. ACS Sustain Chem Eng. 2017:5:9325-37.

19. Zhu K, Yang G, Tan X, Chen C. Polyaniline modified mg/Al layered double hydroxide composites and their application in efficient removal of $\mathrm{Cr}(\mathrm{VI})$. ACS Sustain Chem Eng. 2016:4:4361-9.

20. Kumar ASK, Jiang SJ, Warchoł JK. Synthesis and characterization of twodimensional transition metal dichalcogenide magnetic $\mathrm{MoS}_{2} @ \mathrm{Fe}_{3} \mathrm{O}_{4}$ nanoparticles for adsorption of $\mathrm{Cr}(\mathrm{VI}) / \mathrm{Cr}(\mathrm{III})$. ACS Omega. 2017;2:6187-200.

21. Govindaraju K, Ramasami T, Ramaswamy D. Chromium(III)-insulin derivatives and their implication in glucose metabolism. J Inorg Biochem. 1989:35:137-47

22. Liu Y, Liu F, Ding N, Shen C, Li F, Dong L, Huang M, Yang B, Wang Z, Sand W. Boosting $\mathrm{Cr}(\mathrm{VI})$ detoxification and sequestration efficiency with carbon nanotube electrochemical filter functionalized with nanoscale polyaniline: performance and mechanism. Sci Total Environ. 2019;695:133926.

23. Jiang W, Cai Q, Xu W, Yang M, Cai Y, Dionysiou DD, O'Shea KE. Cr(VI) adsorption and reduction by humic acid coated on magnetite. Environ Sci Technol. 2014;48:8078-85.

24. Sun Y, Lan J, Du Y, Guo L, Du D, Chen S, Ye H, Zhang TC. Chromium(VI) bioreduction and removal by Enterobacter sp. SL grown with waste molasses as carbon source: impact of operational conditions. Bioresour Technol. 2019:302:121974.

25. Dong L, Deng R, Xiao H, Chen F, Zhou Y, Li J, Chen S, Yan B. Hierarchical polydopamine coated cellulose nanocrystal microstructures as efficient nanoadsorbents for removal of $\mathrm{Cr}(\mathrm{VI})$ ions. Cellulose. 2019;26:6401-14.

26. Li J, Chen S, Xiao H, Yao G, Gu Y, Yang Q, Yan B. Highly efficient removal of $\mathrm{Cr}(\mathrm{VI})$ ions from wastewater by the pomegranate-like magnetic hybrid nano-adsorbent of polydopamine and $\mathrm{Fe}_{3} \mathrm{O}_{4}$ nanoparticles. New J Chem. 2020;44(29):12785-92.

27. D'Ischia M, Napolitano A, Ball V, Chen C-T, Buehler MJ. Polydopamine and eumelanin: from structure-property relationships to a unified tailoring strategy. Acc Chem Res. 2014:47:3541-50.

28. Lin J, Wang H, Ren E, Song Q, Lan J, Chen S, Yan B. Stomatocyte-like hollow polydopamine nanoparticles for rapid removal of water-soluble dyes from water. Chem Commun. 2019;55:8162-5.

29. Lin J, Chen S, Xiao H, Zhang J, Lan J, Yan B, Zeng H. Ultra-efficient and stable heterogeneous iron-based Fenton nanocatalysts for degrading organic dyes at neutral $\mathrm{pH}$ via a chelating effect under nanoconfinement. Chem Commun. 2020:56:6571-4.

30. Liu Y, Ai K, Lu L. Polydopamine and its derivative materials: synthesis and promising applications in energy, environmental, and biomedical fields. Chem Rev. 2014;114:5057-115.

31. Zeng Y, Du X, Hou W, Liu X, Zhu C, Gao B, Sun L, Li Q, Liao J, Levkin PA, Gu Z. UV-triggered polydopamine secondary modification: fast deposition and removal of metal nanoparticles. Adv Funct Mater. 2019;29:1901875.

32. Xue DS, Li T, Chen GJ, Liu YH, Zhang DP, Guo Q, Guo JJ, Yang YH, Sun JF, Su BX, Sun L, Shao B. Sequential recovery of heavy and noble metals by mussel-inspired polydopamine-polyethyleneimine conjugated polyurethane composite bearing dithiocarbamate moieties. Polymers (Basel). 2019:11: 1125 
33. Yang S, Gang Y, Wu F, Zhe W, Matyjaszewski K Bioinspired polydopamine (PDA) chemistry meets ordered mesoporous carbons (OMCs): a benign surface modification strategy for versatile functionalization. Chem Mater. 2016;28:5013-21.

34. Sun DT, Peng L, Reeder WS, Moosavi SM, Tiana D, Britt DK, Oveisi E, Queen WL. Rapid, selective heavy metal removal from water by a metal-organic framework/polydopamine composite. ACS Central Sci. 2018:4:349-56.

35. Waite JH, Qin X. Polyphosphoprotein from the adhesive pads of Mytilus edulis. Biochemistry. 2001;40:2887-93.

36. Zhang Q, Li Y, Yang Q, Chen H, Chen X, Jiao T, Peng Q. Distinguished Cr(VI) capture with rapid and superior capability using polydopamine microsphere: behavior and mechanism. J Hazard Mater. 2018;342:732-40.

37. Guo D, An Q, Xiao Z, Zhai S, Yang D. Efficient removal of Pb(II), Cr(VI) and organic dyes by polydopamine modified chitosan aerogels. Carbohydr Polym. 2018;202:306-14.

38. Liu C, Wang J, Li J, Luo R, Shen J, Sun X, Han W, Wang L. Controllable synthesis of functional hollow carbon nanostructures with dopamine as precursor for supercapacitors. ACS Appl Mater Interfaces. 2015;7:18609-17.

39. Ruan J, Wu X, Wang Y, Zheng S, Sun D, Song Y, Chen M. Nitrogen-doped hollow carbon nanospheres towards the application of potassium ion storage. J Mater Chem A. 2019;7:19305-15.

40. Vilardi G, Di Palma L, Verdone N. On the critical use of zero valent iron nanoparticles and Fenton processes for the treatment of tannery wastewater. J Water Process Eng. 2018;22:109-22.

41. Yi Y, Tu G, Zhao D, Eric Tsang P, Fang Z. Biomass waste components significantly influence the removal of $\mathrm{Cr}(\mathrm{VI})$ using magnetic biochar derived from four types of feedstocks and steel pickling waste liquor. Chem Eng J. 2018;360:212-20

42. Zhang W, Deng M, Sun C, Wang S. Ultrasound-enhanced adsorption of chromium(VI) on Fe3O4 magnetic particles. Ind Eng Chem Res. 2013;53: 333-9.

43. Sharma YC, Srivastava V. Comparative studies of removal of $\mathrm{Cr}(\mathrm{VI})$ and $\mathrm{Ni}(\mathrm{II})$ from aqueous solutions by magnetic nanoparticles. J Chem Eng Data. 2011; 56:819-25.

44. Jiang X, An Q, Xiao Z, Zhai S, Shi Z. Mussel-inspired surface modification of untreated wasted husks with stable polydopamine/polyethylenimine for efficient continuous Cr(VI) removal. Mater Res Bull. 2018;102:218-25.

45. Fu J, Chen Z, Wang M, Liu S, Zhang J, Zhang J, Han R, Xu Q. Adsorption of methylene blue by a high-efficiency adsorbent (polydopamine microspheres): kinetics, isotherm, thermodynamics and mechanism analysis. Chem Eng J. 2015;259:53-61.

46. Aguila B, Sun Q, Perman JA, Earl LD, Abney CW, Elzein R, Schlaf R, Ma S. Efficient mercury capture using functionalized porous organic polymer. Adv Mater. 2017;29:1700665.

47. Habibi S, Nematollahzadeh A, Mousavi SA. Nano-scale modification of polysulfone membrane matrix and the surface for the separation of chromium ions from water. Chem Eng J. 2015;267:306-16.

48. Zhou X, Jin B, Luo J, Xu X, Zhang L, Li J, Guan H. Dramatic visible light photocatalytic degradation due to the synergetic effects of $\mathrm{TiO}_{2}$ and PDA nanospheres. RSC Adv. 2016;6:64446-9.

49. Sathish M, Sreeram KJ, Rao JR, Nair BU. Cyclic carbonate: a recyclable medium for zero discharge tanning. ACS Sustain Chem Eng. 2016;4:103240.

50. Wang X, Liu G, Zhang G. Conformational behavior of grafted weak polyelectrolyte chains: effects of counterion condensation and nonelectrostatic anion adsorption. Langmuir. 2011;27:9895-901.

51. Yao L, He C, Chen S, Zhao W, Xie Y, Sun S, Nie S, Zhao C. Codeposition of polydopamine and zwitterionic polymer on membrane surface with enhanced stability and antibiofouling property. Langmuir. 2019;35:1430-9.

52. Bernsmann F, Ponche A, Ringwald C, Hemmerlé J, Raya J, Bechinger B, Voegel JC, Schaaf P, Ball V. Characterization of dopamine-melanin growth on silicon oxide. J Phys Chem C. 2009;113:8234-42.

53. Gao H, Sun Y, Zhou J, Xu R, Duan H. Mussel-inspired synthesis of polydopamine-functionalized graphene hydrogel as reusable adsorbents for water purification. ACS Appl Mater Interfaces. 2013;5:425-32.

54. Liebscher J, Mrowczynski R, Scheidt HA, Filip C, Hadade ND, Turcu R, Bende A, Beck S. Structure of polydopamine: a never-ending story. Langmuir. 2013; 29:10539-48.

\section{Publisher's Note}

Springer Nature remains neutral with regard to jurisdictional claims in published maps and institutional affiliations.

\section{Submit your manuscript to a SpringerOpen ${ }^{\circ}$ journal and benefit from:}

- Convenient online submission

- Rigorous peer review

- Open access: articles freely available online

- High visibility within the field

- Retaining the copyright to your article

Submit your next manuscript at $\boldsymbol{\nabla}$ springeropen.com 